\title{
Post-purchase cognitive dissonance - evidence from the mobile phone market
}

\section{Jens Graff}

SolBridge International School of Business,

151-13 Samsung 1-dong, Dong-gu,

Daejeon 300-814, Korea

E-mail: jensgraff@solbridge.ac.kr

\section{Kittipong Sophonthummapharn*}

Suvarnabhumi Business School,

Rajamangala University of Technology Suvarnabhumi,

19 U-Thong Road, Tawasukri, Ayutthaya 13000, Thailand

E-mail: Kittipong.s@rmutsb.ac.th

*Corresponding author

\section{Vinit Parida}

ETS/Entrepreneurship and Innovation,

Luleå University of Technology, SE-971 87, Sweden

E-mail: vinit.parida@ltu.se

\begin{abstract}
This article investigates whether cognitive dissonance exists in the post-purchase phase in the mobile phone industry. It asks if mobile phone users are fully satisfied since they are usually overloaded with information during the purchasing period. Three dimensions of dissonance were measured in 283 university students. The results provide interesting insights. The major differences between the high and low dissonance groups are being influenced by other people's opinions, difficulty in finding information, product involvement, and satisfaction with mobile phones/operators. These findings reveal that consumers are 'not unhappy' with their mobile phones/operators, but not extremely happy either. However, there is ample room for improvements in the level of consumer satisfaction. Marketers should give consumers' perceptions of communicated messages high priority. The messages need to be straightforward and clear in the consumers' interpretation as this will reduce negative feelings after purchase.
\end{abstract}

Keywords: mobile phones; post-purchase behaviour; cognitive dissonance; customer satisfaction; communication strategy.

Reference to this paper should be made as follows: Graff, J., Sophonthummapharn, K. and Parida, V. (2012) 'Post-purchase cognitive dissonance - evidence from the mobile phone market', Int. J. Technology Marketing, Vol. 7, No. 1, pp.32-46.

Biographical notes: Jens Graff is an Associate Professor, Chair, Global Business Management at SolBridge International School of Business, Woosong Educational Foundation, South Korea. He received his $\mathrm{PhD}$ from Umeå School 
of Business, Umeå University, Sweden, where he lectured. Before that, he lectured at Copenhagen Business College, Denmark, for more than two decades in most business administration disciplines. His business career has included but has not been limited to marketing consulting and business advisory assignments.

Kittipong Sophonthummapharn is an Assistant Professor and Vice Dean of Suvarnabhumi Business School at Rajamangala University of Technology Suvarnabhumi, Thailand. He received his PhD from Umeå School of Business, Umeå University, Sweden. His main research interests are in the areas of e-business, e-commerce, internet marketing, technology acceptance, information and communication technology (ICT), and electronic customer relationship management (eCRM). He has published articles in various national and international journals.

Vinit Parida is an Assistant Professor of Entrepreneurship and Innovation at Luleå University of Technology, Sweden. He received his $\mathrm{PhD}$ on the topic of achieving competitiveness through externally oriented capabilities from the same university. His research interests are the capabilities-based view, entrepreneurial orientation, open innovation, and R\&D offshore collaboration. He has published in Journal of Small Business Management, Production and Operations Management, International Journal of Electronic Business, International Journal of Technoentrepreneurship, Annals of Innovation and Entrepreneurship, and other journals and anthologies in the area of entrepreneurship and innovation management.

\section{Introduction}

Mobile phone suppliers/operators overload consumers with information. Consumers can also be confused and dissatisfied by

a increasing similarity between products/services in the market (similarity confusion)

b information overload (overload confusion)

c ambiguous information (ambiguity confusion) (Walsh et al., 2007).

One known consequence of these confusing conductions is that consumers feel cognitive dissonance (Mitchell et al., 2005).

The purpose of this article is to examine if cognitive dissonance exists in the post-purchase phase among mobile phone users. To achieve this purpose we used the instrumental scale proposed by Sweeney et al. (2000) to measure cognitive dissonance. By measuring different levels of cognitive dissonance, we are able to identify and analyse low and high dissonance groups. Moreover, as little attention is given to the dynamic and complex industry of mobile phones, we have focused on the feelings of consumers in the post-purchase period in this industry. Specifically, we investigate if consumers, after purchasing a mobile phone, are confident or are in a state of cognitive dissonance concerning their purchase.

The article is organised as follows. Section 2 deals with the theoretical framework describing the scope of the study. Cognitive dissonance and communication theories are reviewed and linked to the post-purchase phase of mobile phone users. 
Section 3 describes the research methodology covering research design, questionnaire development, and data collection. Section 4 presents results and discussion. Section 5 concludes with the major findings and implications of the study. Section 6 notes some limitations and provides some suggestions for future research.

\section{Theoretical framework}

\subsection{Cognitive dissonance}

A recent study by Egan et al. (2007, p.987) states that "cognitive dissonance is one of the most heavily studied phenomena in the history of psychology". Social psychologist Festinger (1957) first proposed a theory of cognitive dissonance. Cognition is defined as any element of knowledge, including attitude, emotion, belief, or behaviour. Cognitions which contradict each other are termed 'dissonant'. Cognitions which agree with each other are termed 'consonant'. Cognitions which neither agree nor disagree with each other are termed 'irrelevant'. Cognitive dissonance is described as an uncomfortable tension resulting from having two conflicting thoughts at the same time, or from experiencing apparently conflicting phenomena, or from engaging in behaviour that conflicts with one's beliefs. The theory claims that an individual will try to reduce his/her felt dissonance by inventing new thoughts or beliefs or by modifying existing beliefs.

Rooted in the field of psychology, there has been a strong interest in the effects of cognitive dissonance on attitudes and prejudice (Leippe and Esenstadt, 1994), moral cognition (Tsang, 2002), decision making (Akerlof and Dickens, 1982), and happiness (Lyubomirsky and Ross, 1999). However, cognitive dissonance could also explain phenomena from the field of marketing. For example, Bawa and Kansal (2008, p.43) have suggested to marketers wanting to help consumers to reduce cognitive dissonance to offer strong guarantees or warranties, increase the number and effectiveness of services, and provide detailed brochures on how to use the products correctly.

Cummings and Venkatesan (1976), who have studied the literature of cognitive dissonance since Festinger (1957, p.307) formulated its theory, found many articles based on experimental situations and the difficulty with imaging the real world a problem, but they asserted that "the evidence in favor of dissonance theory in the consumer behaviour literature looks good". They found that in terms of talking of dissonance, the decision needs to be important, irrevocable, and voluntary. A number of studies related to cognitive dissonance were conducted, including consumer dissonance in automobile batteries (Holloway, 1967), dissonance model in post-decision product evaluation (Cohen and Goldberg, 1970), dissonance and state anxiety (Menasco and Hawkins, 1978), post-purchase dissonance (Montgomery and Barnes, 1993), dissonance in car stereo and furniture stores (Sweeney et al., 2000; Soutar and Sweeney, 2003), dissonance in service quality perceptions (O’Neill and Palmer, 2004), dissonance in facility management (Spencer and Hinks, 2007), and dissonance in organisational identity and strategy (Hong-Wei and Balmer, 2007).

To measure the level of dissonance, Sweeney et al. (2000) proposed a 22-item scale for assessing cognitive dissonance in three dimensions, one emotional dimension and two cognitive dimensions named wisdom of purchase and concern over the deal. The 22-item scale is used to measure dissonance levels in the present article. Based on Sweeney et al. (2000, p.380), emotional dimension is defined as "a person's psychological discomfort 
subsequent to the purchase decision". The wisdom of purchase dimension is defined as "a person's recognition after the purchase has been made that they may not have needed the product or may not have selected the appropriate one". The concern over the deal dimension refers to "a person's recognition after the purchase has been made that they may have been influenced against their own beliefs by sales staff". The 22 -item scale consists of 15 items for the emotional dimension, four items for the wisdom of purchase dimension, and three items for the concern over the deal dimension. This scale has been reported to have high reliability and its validity has been demonstrated in previous studies. The present article uses this scale to measure the level of cognitive dissonance among mobile phone users.

We examine cognitive dissonance in mobile phone buying. Dissonance can occur in the pre-purchase, purchase, and post-purchase phases. A consumer seeking information about mobile phones can experience dissonance - for example when an individual sees an advertisement that goes against his/her predetermined thoughts about mobile phone brands or operators. He/she can obviously be in a dissonance situation during buying for the same reasons. Also, he/she can be in dissonance when he/she receives information that changes his/her attitude towards the brand he/she has bought.

\subsection{Communication process}

Since ancient times, people have been interested in communication and how it works and how it can be improved. In a marketing sense, Ottesen (2001) offers a comprehensive explanation of the communication process.

It starts with an individual being exposed to a symbol structure in several forms such as a specific advertisement, sales talk, word of mouth, and other things. This exposure creates initial awareness that can be interpreted as 'To whom is the message directed? What is it all about? Who is behind the message?' The outcome of the interpretation is evaluated for relevance and probability of satisfying the needs of the exposed individual. If the content of the message is not relevant, the individual's interest will cease and he/she will reject the message. Alternatively, if he/she finds the message relevant he/she will give it prolonged attention and go through a probability evaluation to see if it is likely that the offer in the message will satisfy him/her. If he/she thinks this is the case, he/she will then compare the offer with other marketing offerings/vendors, and expectations are created (either positive or negative), and a buying decision is either accepted or rejected. In the positive case the product is bought and the individual will then experience the product and have feelings about it. These feelings can be either favourable or unfavourable and will lead to preference, indifference, or rejection. A satisfied customer will spread the news by word of mouth, which will have a positive effect on the reputation of the communicator.

Looking at Ottesen's (2001) communication explanation, it can be perceived that cognitive dissonance can occur at any stage in the communication process because communication symbols must be interpreted, evaluated, and compared. Symbols or messages conflicting with one's predispositions might create cognitive dissonance. Predispositions can be within knowledge of the product/service, choice criteria, values, attitudes, and media habits.

This article focuses on the post-purchase situation where individuals have experiences with the product/service. However, it is generally necessary to have knowledge of the 
pre-purchase situation and the buying situation itself to evaluate the postpurchase situation. What has led to possible dissatisfaction? Expectations are aroused by market communication in the pre-purchase phase by advertisements or sales talks. Is too much promised? Can the promises be fulfilled? Have the prospective customers been misled? Soutar and Sweeney (2003) recommend that managers spend time and resources to reduce the perceived risk associated with a purchase, since this is likely to significantly reduce customers' dissonance after the purchase.

In buying situations, buyers must be expected to look for cues that make their buying decision rational in case of cognitive dissonance. They might find the purchased item overpriced when using the product or service. They are, therefore, expected to look for rational arguments in their buying to reduce their cognitive dissonance. In other words, immediately after buying, the individual can be in an uncomfortable state where he/she is unsure if the buying was good. He/she is very aware of all communication that concerns his/her buying, e.g., competing offerings, and he/she can be in a state of cognitive dissonance. After buying, the individual has experience with the phone/operator. Maybe he/she is not fully satisfied and believes that the 'grass is greener on the other side'. He/she will be very vulnerable to cognitive dissonance.

It occurs from the communication process that it is very important for a marketer to address the question of cognitive dissonance, because a high level of dissonance will delay buying or a potential customer might reject an offer. Also in the post-purchase stage, it is important for a supplier to try to reduce any cognitive dissonance by informing and praising the product/service that the individual has bought. A low level of cognitive dissonance is a precondition for the individual to become a good ambassador for the company and for repeat buying.

\subsection{Post-purchase phase}

In this article we look especially at the post-purchase phase of mobile phone buying. We argue that mobile phone operators are promising more than they can deliver or are disguising their offerings by providing limited information, so that consumers might be in a post-purchasing dissonant state and regret the purchase. Mobile phone operators offer a range of elements that include a price for the mobile phone itself, time of locking in with the operator, subscription rates, minute rates, and price for short message service (SMS). They mix these in different ways to attract different market segments, but this also results in offerings with very little transparence. Berthon and Pitt (2005) note this paradox of advertising; instead of informing consumers about the products/services so they can make rational choices, marketers often use advertising to disguise their offerings to make them difficult to compare. It seems that marketers in the mobile phone industry nowadays are devising various offers to attract consumers at 'any cost'.

Consumers might be in a cognitive dissonant state throughout the buying process and might not be fully satisfied with their buying. Some variance in cognitive dissonance among consumers is to be expected. It will be interesting to see whether different degrees of dissonance can be found and dissonance groups identified. However, for the purpose of this article, the post-purchase phase is chosen as the main emphasis. 


\subsubsection{Demographics}

Men and women have different physiological patterns which means that the level of dissonance may differ based on gender. Men tend to be double-minded and prone to dissonance. They also experience more anger and aggression (Soutar and Sweeney, 2003). Women tend to be more rational and are easily able to build up logic for dissonance (Dittmar and Drury, 2000). As the product studied here is a technological device, men are typically more interested in this kind of product. Because the level of expectation in men will be higher than in women, men will experience more dissonance than women. Regarding age, younger customers are normally more knowledgeable and sophisticated about purchasing technological products. They tend to collect a large pool of information before making a purchase. This also results in a higher level of expectation from the product (Thompson et al., 1993). Older customers, on the other hand, tend to be more calm and trusting of sales personnel. Therefore, younger customers will experience a higher level of dissonance than older customers (Soutar and Sweeney, 2003). Thus, based on the above arguments, gender and age will affect cognitive dissonance. We hypothesise that:

H1a There is a difference in gender between low and high dissonance users.

$\mathrm{H} 1 \mathrm{~b}$ There is a difference in age between low and high dissonance users.

\subsubsection{Time period of mobile phone ownership}

Time period plays a critical role in cognitive dissonance. According to Soutar and Sweeney (2003), the level of dissonance varies depending upon time. In most cases, the probability of dissonance is higher just after purchase. But over time, individuals attempt to reduce the feeling of dissonance. As explained earlier, dissonance is a state of mental discomfort, and individuals do not want to continue in this mental state. Individual efforts to narrow the gap between prior expectation and post-purchase perceptions increase with time (O’Neill and Palmer, 2004). The 22-item scale developed by Sweeney et al. (2000) used three months and ten days post-purchase as the time duration for measuring dissonance. But it is also possible to measure dissonance over a longer period cycle. Thus, we propose the following hypothesis:

H2 The time period for which individuals own mobile phone varies between low and high dissonance users.

\subsubsection{Influence from other people}

Those who can influence an individual's attitude and behaviour are termed reference groups. These groups can be formal (members of clubs or sociality) or informal (friends, family members). The individual not only looks at the group for social acceptance, but also engages in direct verbal interaction to evaluate purchased products. Students tend to rely largely on such groups regarding purchases (Park and Lessig, 1977; Bearden and Etzel, 1982). Mobile phone buying can also be regarded as a product with big social reward/punishment. It is a technical product with many features and functions that can be difficult to perceive. Therefore, other people can be expected to influence buyers to a large extent. Thus, individuals looking for acceptance from others for a purchase will be 
more prone to dissonance. Opinions from other people will be important and affect an individual's cognitive dissonance. Therefore, we propose the following hypothesis:

H3 There is a difference between low and high dissonance users in the perception of other people's comments and opinions.

\subsubsection{Mobile phone experience}

The first mobile phone was developed by Motorola in the early 1980s. Almost 15 years passed before consumers could buy mobile phones at nominal prices. Currently, most users in the western world have already changed their mobile phones regularly. Thus, it is important to remember that customers typically have previous experience with his product. The process of experience begins just after the purchase of the product (Hogart, 1981). Product experience consists of product usage and evaluation, number of exposures to advertisements, and influences of others in the social environment (Hoyer, 1984). Generally speaking, more experienced consumers should have lower dissonance. However, more experience could also lead to higher expectations, which might increase dissonance. This is especially true for technological products due to their rapid technological change. The next hypothesis is formulated as:

H4 There is a difference between low and high dissonance users in their amount of experience with mobile phones.

\subsubsection{Information during purchasing}

Difficulty in finding information and the adequacy of information can influence the decision process. Companies provide information in many forms such as TV ads, magazine ads, outdoor billboards, etc. This not only plays an important role in the early stage of purchase by developing instrumental knowledge, but also post-purchase because it provides confirmation of the purchase choice (Hoyer, 1984). When sufficient information is available in the market, the level of dissonance is low. Individuals will feel more satisfied when they see advertisements about their purchased product. When information is difficult to find, individuals will have a higher level of dissonance. They will not be sure about their choice and will feel as though they have been tricked or cheated. Therefore, we propose the following hypotheses:

H5a Low and high dissonance users have different degrees of difficulty finding information about mobile phones during the buying process.

H5b Low and high dissonance users have different views on the adequacy of information about mobile phones during the buying process.

\subsubsection{Product involvement}

Product involvement is related to the customer's amount of interest in the product. The amount of money involved in the purchase can also indicate product involvement. If the customer has put a lot of effort and time into choosing a product, product involvement will be high. Moreover, it will be easier to feel dissonance with such a purchase as the expectation will be high (Richins and Bloch, 1991). A mobile phone does not fit the high involvement products category for most individuals, but still it is not a low involvement 
product. Thus, there is substantial effort and thinking involved in purchasing a mobile phone. Therefore, the following hypothesis is proposed:

H6 Product involvement in the mobile phone buying process differs between low and high dissonance users.

\subsubsection{Satisfaction}

A satisfied customer is the prerequisite for long-term relationships (Grönroos, 1995). This has been confirmed by a number of studies in the marketing field. This indicates that market orientation is a 'must' for success in business, including the mobile phone industry. Krepapa et al. (2003) found that divergence in perceptions of market orientation between customers and service providers hindered customer satisfaction. Also, Kuo et al. (2009, p.895) found that service quality positively influences perceived value and customer satisfaction. They argue that when telecom companies provide good service quality, perceived value and customer satisfaction can be enhanced.

Customer satisfaction can be expressed as a function of expectation and disconfirmation. The studies investigating satisfaction in the pre-purchase period focus on expectation, whereas for the post-purchase period, the focus tends to lie on disconfirmation or dissonance (Oliver, 1980). The correlation between dissonance and satisfaction can be expected to be negative. Individuals with a high level of dissonance will have a low level of satisfaction and vice versa. As suggested before, dissonance has to do with a state of mental discomfort and uncertainty (Soutar and Sweeney, 2003). Once the individual has been exposed to the product, his/her expectations are either satisfied or unsatisfied. A satisfied individual will feel no or only little dissonance. The current mobile phone market is filled with rapidly changing products which increases the possibility for higher dissonance and a lower level of satisfaction. Thus, the present article hypothesises that:

H7 There is a difference between low and high dissonance users in satisfaction with mobile phones and operators.

\section{Methodology}

Survey research was done using a self-administered questionnaire. The following sections describe the questionnaire's development and the data collection.

\subsection{Questionnaire development}

A survey questionnaire was developed and a pilot test was conducted using twenty-five undergraduate students. The respondents were asked if they understood the questions or not. Some minor adjustments were made based on their feedback. The final questionnaire consists of four sections as outlined in the following.

Section I Demographic information (gender, age).

Section II Basic information about mobile phones.

- mobile phone ownership measured by nominal scale (yes/no) 
- brand measured by nominal scale (brand name)

- time period of mobile phone ownership measured by ordinal scale ( $<$ three months, three to six months, six months to one year, $>$ one year)

- $\quad$ influence of other people's opinions measured by seven-point semantic differential scale (not important at all/very important)

- technology experience measured by number of mobile phones respondents had before the present one

- difficulty finding information measured by seven-point semantic differential scale (not difficult at all/very difficult)

- $\quad$ adequacy of information measured by seven-point semantic differential scale (insufficient/sufficient)

- $\quad$ product involvement [based on Mittal (1995)] measured by seven-point semantic differential scale.

Section III Satisfaction with mobile phone and operator measured by seven-point semantic differential scale (completely dissatisfied/completely satisfied).

Section IV Cognitive dissonance [based on Sweeney et al. (2000)]. The 22-item scale has three dimensions: 15 items measured emotional, four items measured wisdom of purchase, and three items measured concern over the deal. All dimensions were measured by seven-point Likert scale from $1=$ strongly disagree to 7 = strongly agree.

\subsection{Data collection}

The data were gathered from undergraduate students from two universities in Sweden during October 2007. The convenience sampling technique was used due to the cost and time available for conducting this research. However, the present study aims to focus on the young generation because they tend to be the major customers of the mobile phone industry. So, the sample in this study is well-suited for the study and could contribute interesting results to the research community.

The data were collected from a number of classes. The students were either in the first or second year of study in the business schools at both universities. There were 321 respondents, but 38 were excluded due to incomplete questionnaires or being outliers in terms of demographic information. Thus, we used 283 respondents, which is sufficient for data analysis.

\section{Results and discussion}

\subsection{Demographic information}

The majority of the respondents were male (53.4\%) while $46.6 \%$ were female. All respondents were local Swedish students registered as first or second year undergraduate students in business school. Ages ranged from 18 to 31 years old with a mean of 22.52 for the whole group. The mean age was 22.50 for male respondents and 22.54 for female respondents. 
All respondents were of Swedish nationality. There were no significant differences in gender or age concerning dissonance. Thus, Hypotheses H1a and H1b are not supported. This might be due to the selectivity of the sample, which targeted university students. The age range is also narrow resulting in insignificant difference among respondents, which seems natural because people share something in common with other people of the same age. Furthermore, as is happening in today's society, both sexes appear equally enthusiastic concerning the use of mobile phones. It could be said that any difference in gender dissonance should not be expected. Nonetheless, one might expect stronger dissonance feelings among older people as they are normally not so sophisticated in mobile phone techniques, but that argument goes beyond the scope of the present study.

\subsection{Descriptive analysis of dissonance dimensions}

Basic descriptive statistics of the dimensions of dissonance are presented in Table 1. It includes the mean for each dimension and scale reliability. Internal consistency reliability was determined by computing the coefficient score for Cronbach's alpha. As a rule of thumb, a Cronbach's alpha above 0.70 is considered good and acceptable for most research (Nunnally, 1978). The scale reliability in each dissonance dimension is considerably high, as they are above the recommended value, providing strong indication for subsequent analysis.

Table 1 Descriptive statistics

\begin{tabular}{lccc}
\hline Dissonance dimension & Mean $^{\mathrm{a}}$ & Standard deviation & Alpha reliability \\
\hline Emotional & 1.27 & 0.47 & 0.88 \\
Wisdom of purchase & 2.43 & 2.43 & 0.82 \\
Concern over the deal & 1.81 & 1.81 & 0.89 \\
\hline
\end{tabular}

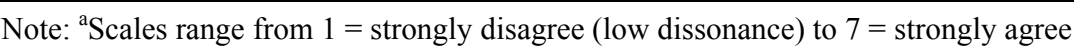
(high dissonance)

\subsection{Clustering of dissonance types}

To look for differences between those with low and high feelings of dissonance toward having mobile phones, a cluster analysis was performed based on the three dimensions of the cognitive dissonance scale. The calculation was done by SPSS computer software version 15.00. The k-means clustering procedure was used to divide respondents into two groups. The first group has 169 respondents representing $59.7 \%$ of the sample while the second group has 114 respondents accounting for $40.3 \%$ of the sample. Table 2 shows the means of each dissonance dimension for Groups 1 and 2. It can be clearly seen that Group 1 has lower mean scores than Group 2 in all dissonance dimensions. So, Group 1 is labelled as the low dissonance group whereas Group 2 is viewed as the high dissonance group.

Table 2 Cluster analysis - mean scores and percentages

\begin{tabular}{lccccc}
\hline Cluster & Emotional & $\begin{array}{c}\text { Wisdom of } \\
\text { purchase }\end{array}$ & $\begin{array}{c}\text { Concern over } \\
\text { the deal }\end{array}$ & $n$ & $\%$ \\
\hline Group 1 low dissonance & 1.15 & 1.66 & 1.28 & 169 & $59.7 \%$ \\
Group 2 high dissonance & 1.44 & 3.57 & 2.60 & 114 & $40.3 \%$ \\
\hline
\end{tabular}




\subsection{Dissonance variations}

The two groups were assessed for differences. The F-test was employed to compare the means of demographic information and psychographic information. Table 3 presents the results of the F-test, and clearly shows a statistically significant difference $(p<0.05)$ in terms of influence of other people's opinions, difficulty in finding information, product involvement, and satisfaction with mobile phone and operator. These results also reveal that there is no statistically significant difference in terms of gender, age, time period of having mobile phone, mobile phone experience, and adequacy of information.

Table 3 Group means statistics using F-test

\begin{tabular}{|c|c|c|c|c|c|c|c|c|}
\hline \multirow[t]{2}{*}{ Variables } & \multicolumn{2}{|c|}{$\begin{array}{c}\text { Low } \\
\text { dissonance } \\
(n=169)\end{array}$} & \multicolumn{2}{|c|}{$\begin{array}{c}\text { High } \\
\text { dissonance } \\
(n=114) \\
\end{array}$} & \multicolumn{2}{|c|}{$\begin{array}{c}\text { Total } \\
(n=283)\end{array}$} & \multirow[t]{2}{*}{$F$} & \multirow[t]{2}{*}{ Sig } \\
\hline & $M$ & $S D$ & $M$ & $S D$ & $M$ & $S D$ & & \\
\hline Gender & 1.51 & 0.501 & 1.40 & 0.493 & 1.47 & 0.500 & 3.048 & .082 \\
\hline Age & 22.74 & 2.391 & 22.19 & 2.319 & 22.52 & 2.373 & 3.645 & .057 \\
\hline $\begin{array}{l}\text { Time period of having } \\
\text { mobile phone }\end{array}$ & 2.86 & 1.192 & 2.93 & 1.180 & 2.89 & 1.186 & 0.249 & .618 \\
\hline $\begin{array}{l}\text { Influence of other } \\
\text { people's opinions }\end{array}$ & 2.90 & 1.549 & 3.43 & 1.487 & 3.11 & 1.544 & 8.239 & $.004 *$ \\
\hline $\begin{array}{l}\text { Mobile phone } \\
\text { experience }\end{array}$ & 3.80 & 2.337 & 3.71 & 2.152 & 3.76 & 2.261 & 0.104 & .748 \\
\hline $\begin{array}{l}\text { Difficulty in finding } \\
\text { information }^{\mathrm{a}}\end{array}$ & 5.99 & 1.152 & 5.65 & 1.344 & 5.86 & 1.242 & 5.332 & $.022 *$ \\
\hline $\begin{array}{l}\text { Adequacy of } \\
\text { information }\end{array}$ & 5.12 & 1.523 & 4.82 & 1.422 & 5.00 & 1.488 & 2.671 & .103 \\
\hline Product involvement & 4.20 & 1.280 & 4.55 & 1.075 & 4.34 & 1.212 & 6.020 & $.015^{*}$ \\
\hline $\begin{array}{l}\text { Satisfaction with mobile } \\
\text { phone and operator }\end{array}$ & 5.17 & 1.116 & 4.78 & 1.302 & 5.01 & 1.207 & 7.072 & $.008^{*}$ \\
\hline
\end{tabular}

Notes: *F-test with statistical confidence level of $95 \%(p<0.05)$

${ }^{\text {a }}$ Scale is reversed score

The specific findings of Table 3 are evaluated and discussed below.

1 Time period owning mobile phone: The respondents did not express significant differences in their feelings of dissonance based on how long they owned their mobile phones. Thus, Hypothesis 2 is not supported. On average they have had their mobile phone between six months and one year. Dissonance would be expected to decrease as time of ownership increased, but the study did not support this. Maybe dissonance appeared in the very early phase after purchase, but then disappeared as owners got to know their phones/operators. It is also possible that new things appeared which outweighed respondents' decreasing dissonance as time passed.

2 Influence of other people: The research has shown that the influence of other people is important, especially in the high dissonance group. Thus, we found support for Hypothesis 3. It seems natural that people in doubt listen to the opinions of others who are close to them. This point is very important for marketers, as family and friends close to the consumer are very influential and in some cases take over the 
communication role from suppliers. There should, therefore, be consistency between the offer and the communication about the offer. Mobile phone suppliers/operators should not make promises they cannot fulfil or try to deceive consumers because current mobile phone users are experienced and can communicate things 'as they are'.

3 Mobile phone experience: As mentioned earlier, having mobile phone experience might affect the level of dissonance, either increasing or decreasing it. Our findings show that both low and high dissonance users have similar experience with mobile phones (i.e., Hypothesis 4 not supported). They tend to have purchased around three mobile phones prior to the one owned now. This indicates that having prior experience with mobile phones does not necessarily affect dissonance. The finding here is surprising and requires further research. Differences in having mobile phone experience should be examined to determine whether they result in differences in dissonance.

4 Information during purchasing: It is easy for consumers to get access to information in the buying process and they are satisfied with the amount of information. Respondents in the high dissonance group, though, found it a little more difficult to get information. Respondents found it easy to search for information about mobile phone buying (average mean is 5.86). Hypothesis 5a is supported as there is a significant difference between the two groups, with the low dissonance group finding it easier to search for information. It could be argued that easy access to data about mobile phones/operators is important for reducing dissonance. Furthermore, there seems to be satisfaction with the amount of information available and no significant difference between the two groups (i.e., Hypothesis $5 \mathrm{~b}$ not supported).

5 Product involvement: Product involvement was measured to be close to average value. It shows a medium involvement in the buying process - a little higher for the high dissonance group (i.e., Hypothesis 6 supported). Mobile phone buying is a matter of importance for consumers, which means suppliers/operators must communicate their message strongly and clearly.

6 Satisfaction: Respondents were to a degree satisfied overall with their mobile phones and operators. The mean for all respondents is 5.01, which indicates an inclination of satisfaction but not complete devotion to their mobile phone/operator. The low dissonance group is slightly more satisfied (5.2) than the high dissonance group (4.8). This difference is statistically significant. Thus, Hypothesis 7 stating that cognitive dissonance influences the degree of satisfaction in the post-purchase period is confirmed.

\subsection{Summary of hypothesis testing}

To conclude, the analysis indicates that four hypotheses are supported. Table 4 summarises the hypothesis testing. The results provide interesting insight about the dissonance variation of mobile phones after purchase.

The supported hypotheses show that the respondents are concerned with other people's comments and opinions, sufficient information, involvement in the product, and satisfaction toward mobile phone and operator. In other words, the less post-purchase 
cognitive dissonance people feel, the less they are dependent on other people's comments and opinions; the less they feel they need further information during the buying process; the less they feel they have to use effort and thinking to purchase the mobile phone; and the more satisfied they are with the mobile phone and operator.

Table 4 Summary of hypothesis testing

\begin{tabular}{lc}
\hline Hypotheses & Result \\
\hline Hypothesis 1a & Not supported \\
Hypothesis $1 \mathrm{~b}$ & Not supported \\
Hypothesis 2 & Not supported \\
Hypothesis 3 & Supported \\
Hypothesis 4 & Not supported \\
Hypothesis $5 \mathrm{a}$ & Supported \\
Hypothesis $5 \mathrm{~b}$ & Not supported \\
Hypothesis 6 & Supported \\
Hypothesis 7 & Supported \\
\hline
\end{tabular}

\section{Conclusions and implications}

Overall, the findings show that buying mobile phones and services from mobile phone operators is an easy task for young people. They are not so emotionally involved and do not regret their purchases. Respondents were apparently satisfied with the information given by the mobile phone suppliers/operators. The levels of dissonance are low overall, although two groups of respondents could be identified in regard to dissonance levels. Our research showed statistical significance on the $95 \%$ confidence level that the high dissonance group was more influenced by other people's opinions, they found it more difficult to find information, they were more involved in the decision to buy a mobile phone, and they were less satisfied with their mobile phone/operator than the low dissonance group was.

For positive evaluation and communication with others, it is important for mobile phone buyers to feel a low level of post-purchase dissonance. It is imperative for repeat buying of a particular mobile phone brand and for operator choice also.

Consumers are 'not unhappy' with their mobile phones/operators, but not extremely happy either. The implications are clear. There is ample room for improvements. For marketers, consumer perceptions of communication messages should be given high priority. The messages need to be straightforward and clear in the consumers' interpretation. Potential buyers will perceive the messages and then evaluate them for relevance and probability of fulfilling their needs. If the communication is not clear there is a risk of cognitive dissonance that most likely will influence the buying process of potential customers negatively. They will postpone buying until they have better information or else take a chance and buy with the risk of being unsatisfied. The findings here provide a hint for mobile phone companies and marketers in adjusting their marketing messages and strategies. It is, therefore, important for marketers to be aware of potential buyers' information needs. What do they know about the product/service? What 
would they like to know? Which choice criteria do they have? Consequently, marketers should address these concerns to fulfil these information needs.

\section{Limitations and future research}

Since the study is exploratory, some limitations should be noted. First, students from two universities were selected as a sample. This might restrict the generalisability of the study. However, the students, by their characteristics, could be seen as a major customer in the mobile phone industry. The number of samples in this study was large enough to contribute meaningful results to the research community. A wider range of samples is required in future research to consolidate the knowledge to the research community. Second, the convenience sampling technique was used, which calls into question how representative the results are. The findings here are not intended to represent mobile phone users throughout the country or in other countries. Future research should employ other probability sampling techniques to ensure that results are more representative. Also, further studies covering respondents of different ages might exhibit different results which would be helpful to mobile phone manufacturers and operators in developing marketing strategies and delivering adequate information to consumers. Therefore, the findings discussed in this study should be interpreted in light of these limitations.

\section{References}

Akerlof, G.A. and Dickens, W.T. (1982) 'The economic consequences of cognitive dissonance', The American Economic Review, Vol. 72, No. 3, pp.307-319.

Bawa, A. and Kansal, P. (2008) 'Cognitive dissonance and the marketing of services: some issues', Journal of Services Research, Vol. 8, No. 2, pp.31-51.

Bearden, W.O. and Etzel, M.J. (1982) 'Reference group influence on product and brand purchase decisions', Journal of Consumer Research, Vol. 9, No. 2, pp.183-194.

Berthon, P. and Pitt, L. (2005) 'The paradox of advertising', International Journal of Advertising, Vol. 24, No. 4, pp.539-546.

Cohen, J.B. and Goldberg, M.E. (1970) 'The dissonance model in post-decision product evaluation', Journal of Marketing Research, Vol. 7, No. 3, pp.315-321.

Cummings, W.H. and Venkatesan, M. (1976) 'Cognitive dissonance and consumer behavior: a review of the evidence', Journal of Marketing Research, Vol. 13, No. 3, pp.303-308.

Dittmar, H. and Drury, J. (2000) 'Self-image - is it in the bag? A qualitative comparison between 'ordinary' and 'excessive' consumers', Journal of Economic Psychology, Vol. 21, No. 2, pp.109-142.

Egan, L.C., Santos, L.R. and Bloom, P. (2007) 'The origins of cognitive dissonance: evidence from children and monkey’, Psychological Science, Vol. 18, No. 11, pp.978-983.

Festinger, L. (1957) A Theory of Cognitive Dissonance, Stanford University Press, Stanford.

Grönroos, C. (1995) 'Relationship marketing: the strategy continuum', Journal of the Academy of Marketing Science, Vol. 23, No. 4, pp.252-254.

Hogarth, R.M. (1981) 'Beyond discrete biases: functional and dysfunctional aspects of judgmental heuristics', Psychological Bulletin, Vol. 90, No. 2, pp.197-217.

Holloway, R.J. (1967) 'An experiment on consumer dissonance', Journal of Marketing, Vol. 31, No. 1, pp.39-43. 
Hong-Wei, H. and Balmer, J.M.T. (2007) 'Perceived corporate identity/strategy dissonance: triggers and managerial responses', Journal of General Management, Vol. 33, No. 1, pp.71-91.

Hoyer, W.D. (1984) 'An examination of consumer decision making for a common repeat purchase product', The Journal of Consumer Research, Vol. 11, No. 2, pp.822-829.

Krepapa, A., Berthon, P., Webb, D. and Pitt, L. (2003) 'Mind the gap. An analysis of service provider versus customer perceptions of market orientation and the impact on satisfaction', European Journal of Marketing, Vol. 37, No. 1, pp.197-218.

Kuo, Y-F., Wu, C-M. and Deng, W-J. (2009) 'The relationships among service, quality, perceived value, customer satisfaction, and post-purchase intention in mobile value-added services', Computers in Human Behavior, Vol. 25, No. 4, pp.887-896.

Leippe, M.R. and Eisenstadt, D. (1994) 'Generalization of dissonance reduction: decreasing prejudice through induced compliance', Journal of Personality and Social Psychology, Vol. 67, No. 3, pp.395-413.

Lyubomirsky, S. and Ross, L. (1999) 'Changes in attractiveness of elected, rejected, and precluded alternatives: a comparison of happy and unhappy individuals', Journal of Personality and Social Psychology, Vol. 76, No. 6, pp.988-1007.

Menasco, M.B. and Hawkins, D.I. (1978) 'A field test of the relationship between cognitive dissonance and state anxiety', Journal of Marketing Research, Vol. 15, No. 4, pp.650-655.

Mitchell, V-W., Walsh, G. and Yamin, M. (2005) 'Towards a conceptual model of consumer confusion', Advances in Consumer Research, Vol. 32, pp.143-150.

Mittal, B. (1995) 'A comparative analysis of four scales of consumer involvement', Psychology \& Marketing, Vol. 12, No. 7, pp.663-682.

Montgomery, C. and Barnes, J.H. (1993) 'POSTDIS: a short rating scale for measuring postpurchase dissonance', Journal of Consumer Satisfaction, Dissatisfaction and Complaining Behavior, Vol. 6, pp.204-216.

Nunnally, J.C. (1978) Psychometric Theory, 2nd ed., McGraw-Hill, New York.

O'Neill, M. and Palmer, A. (2004) 'Cognitive dissonance and the stability of service quality perceptions’, Journal of Services Marketing, Vol. 18, No. 6, pp.433-449.

Oliver, R.L. (1980) 'A cognitive model of the antecedents and consequences of satisfaction decisions', Journal of Marketing Research, Vol. 17, No. 4, pp.460-469.

Ottesen, O. (2001) Marketing Communication Management. A Holistic Approach for Increased Profitability, Copenhagen Business School Press, Copenhagen.

Park, C.W. and Lessig, V.P. (1977) 'Students and housewives: differences in susceptibility to reference group influence', The Journal of Consumer Research, Vol. 4, No. 2, pp.102-110.

Richins, M.L. and Bloch, P.H. (1991) 'Post-purchase product satisfaction: incorporating the effects of involvement and time', Journal of Business Research, Vol. 23, No. 2, pp.145-158.

Soutar, G.N. and Sweeney, J.C. (2003) 'Are there cognitive dissonance segments?', Australian Journal of Management, Vol. 28, No. 3, pp.227-249.

Spencer, R. and Hinks, J. (2007) 'The significance of cognitive dissonance for the hard and soft FM paradigm and quality assessment practices', Journal of Facilities Management, Vol. 5, No. 4, pp. $243-262$.

Sweeney, J.C., Hausknecht, D. and Soutar, G.N. (2000) 'Cognitive dissonance after purchase: a multidimensional scale', Psychology \& Marketing, Vol. 17, No. 5, pp.369-385.

Thompson, S.C., Pitts, J.S. and Schwankowsky, L. (1993) 'Preferences for involvement in medical decision making: situational and demographic differences', Patient Education and Counseling, Vol. 22, No. 1, pp.133-140.

Tsang, J. (2002) 'Moral rationalization and the integration of situational factors and psychological processes in immoral behavior', Review of General Psychology, Vol. 6, No. 1, pp.25-50.

Walsh, G., Hennig-Thurau, T. and Mitchell, V-W. (2007) 'Consumer confusion proneness: scale development, validation, and application', Journal of Marketing Management, Vol. 23, Nos. 7/8, pp.697-721. 